ТРАЕКТОРИЯ ЛЕЧЕНИЯ ДИСЦИРКУЛЯТОРНОЙ ЭНЦЕФАЛОПАТИИ І СТЕПЕНИ, АССОЦИИРОВАННОЙ С ИДИОПАТИЧЕСКОЙ ИНТРАКРАНИАЛЬНОЙ ГИПЕРТЕНЗИЕЙ: КАРДИОНЕВРОЛОГИЧЕСКИЙ КЛИНИЧЕСКИЙ СЛУЧАЙ

\begin{abstract}
Горшков-Кантакузен В. A.
В настоящей работе сообщается о клиническом случае лечения молодой женщины с дисциркуляторной энцефалопатией । степени, ассоциированной с идиопатической интракраниальной гипертензией, на фоне лабильности артериального давления и ипохондрического синдрома. Уникальность данного случая заключается в мультидисциплинарности нарушений и сложности подбора соответствующей траектории лечения.
\end{abstract}

Российский кардиологический журнал. 2018;23(9):54-57

http://dx.doi.org/10.15829/1560-4071-2018-9-54-57

Ключевые слова: кардионеврология, дисциркуляторная энцефалопатия идиопатическая интракраниальная гипертензия, лабильность.

Конфликт интересов: не заявлен

${ }^{1}$ Фонд изучения гипертензии, Папский Колледж св. Георгия, Роли; ${ }^{2}$ Американский институт клинических психотерапевтов, Франкфорт, США

Горшков-Кантакузен В. А. - канд. богословия, д-р. канонич. права, д-р. мед. наук, проф. руководитель, исполнительный медицинский директор, ORCID: 0000-0002-4691-4719.
Автор, ответственный за переписку (Corresponding author) hypfoundation@gmail.ru

АД - артериальное давление, ДЭП - дисциркуляторная энцефалопатия, УзИ - ультразвуковое исследование, РЭГ - реоэнцефалография, чСС частота сердечных сокращений, ЭКГ - электрокардиография, ЭОС - электрическая ось сердца, ЭЭГ - электрокардиография, ISH - International Society of Hypertension (Международное общество по изучению гипертензии), MMPI - Minnesota Multiphasic Personality Inventory (Миннесотский многоаспектный личностный опросник), MMSE - Mini-Mental State Examination (Краткая шкала оценки психического статуса), RMH - Research \& Management of Hypertension (программа "Изучение и управление гипертензией"), WHL World Hypertension League (Всемирная гипертензивная лига), WMA - World Medical Association (Всемирная медицинская ассоциация).

Рукопись получена 20.06.2018

Рецензия получена 24.07.2018

Принята к публикации 26.07.2018

\title{
MANAGEMENT TRAJECTORY FOR DYSCIRCULATORY ENCEPHALOPATHY GRADE I, ASSOCIATED WITH IDIOPATHIC INTRACRANIAL HYPERTENSION: A CARDIONEUROLOGICAL CASE
}

Gorshkov-Cantacuzene V. A. ${ }^{1,2}$

The article presents clinical case of a young woman with dyscirculatory encephalopathy grade I associated with idiopathic intracranial hypertension, with lability of arterial pressure and hypochondria. The uniqueness of the case presented, is in multidisciplinarity of disorders and difficulty in patient management trajectory formulation.

Russ J Cardiol. 2018;23(9):54-57

http://dx.doi.org/10.15829/1560-4071-2018-9-54-57

Key words: cardioneurology, dyscirculatory encephalopathy, idiopathic intracranial hypertension, lability.

Развитие науки и техники выдвинуло в число приоритетных направлений мультидисциплинарный подход, что было отмечено в стт. 5 и 6 Декларации ЮНЕСКО (1998). Применительно к медицине, наибольшее развитие стали получать такие области, как трансляционная и персонифицированная. Развитие медицинской науки способствовало повышению качества лечения за счет ранней диагностики и алгоритмизации. Однако, на сегодняшний день, с одной стороны, остаются заболевания, трудно диагностируемые и не имеющие однозначных траекторий лечения, а с другой, - комбинации патологий, встречающиеся настолько редко, что добиться высокой доказательности лечения просто невозможно. На
Conflicts of Interest: nothing to declare.

'Hypertension Research Foundation, Pontifical Georgian College, Raleigh; ${ }^{2}$ American Institute of Clinical Therapeutics, Frankfort, USA

Gorshkov-Cantacuzene V. A. ORCID: 0000-0002-4691-4719.

сегодняшний день, к первой группе, например, относится гипертензия, являющаяся причиной приобретенной нетрудоспособности и смерти номер один в мире (по данным WHL и ISH), над изучением этиологии и разработкой траектории лечения которой работает огромное число ученых во всем мире; а ко второй, например, - та же гипертензия, но осложненная рядом других патологий, образом жизни и/или возрастом больного. Конечно, нельзя не отметить, что образ жизни пациента и его психоэмоциональное состояние является важным фактором развития многих патологий. Поэтому описание конкретных клинических случаев может служить хорошим подспорьем для специалиста, имеющего 
дело с нестандартным и неалгоритмизированным заболеванием.

Дисциркуляторная энцефалопатия (ДЭП) - хроническая прогрессирующая форма цереброваскулярной патологии, характеризующаяся развитием многочагового или диффузного ишемического поражения головного мозга. В отличие от инсульта, ДЭП характеризуется двумя основными особенностями: умеренным постепенным развитием (часто с длительным периодом клинически “скрытого” течения) и мультифокальностью поражения мозга. Сам термин “дисциркуляторная энцефалопатия" предложен Г.А. Маскудовым, Е.В. Шмидтом и В.М. Коганом в 1958г [1], хотя в МКБ-10 не значится и, видимо, подпадает под “цереброваскулярная болезнь неуточненная" или “другие уточненные поражения сосудов мозга”. ДЭП является серьезным фактором риска инсульта; она существенно ухудшает качество жизни и сильно снижает трудоспособность, поэтому проблема лечения этого заболевания имеет большое социальное и экономическое значение [2]. Согласно статистике, ДЭП имеют 5-6\% населения России; она занимает первое место по частоте встречаемости в ряду так называемых сосудистых неврологических патологий.

Течение ДЭП принято подразделять на три этапа (по Н. Н. Яхно, И. В. Дамулин) [3]:

I этап: приступы мигрени, головокружения, шум и тяжесть в голове, утомляемость, снижение внимания, неустойчивая ходьба, нарушение сна.

II этап (субкомпенсация): существенное снижение физических или умственных способностей (снижение памяти, замедленность всех психических процессов, нарушение внимания и мышления, способности контролировать действия), апатия, эмоциональная лабильность, депрессия, необоснованная раздражительность (иногда).

III этап (декомпенсация): симптомы II этапа, но с возрастающим инвалидизирующим влиянием.

Для простановки диагноза используют как рутинные методы, позволяющие выявлять патологии сердечнососудистой и цереброваскулярной систем, так и психометрические, которые входят в набор критерий О.С. Левина; иногда дополнительно используют шкалу В.С. Хачинского, тесты А.Л. Лурия, STAI (Ч.Д. Спилберга - Ю.Л. Ханина) и другие.

\section{Клинический случай}

Пациентка И., 27 лет. На начало участия в исследовательской программе Фонда изучения гипертензии "RMH" проходила безрезультатное лечение в провинциальной клинике, а затем в городской. Со слов пациентки, ее обследовали терапевт, два невролога и хирург, которые к единому диагнозу так и не пришли; назначенная терапия привела только к ухудшению состояния.
До заболевания профессионально занималась спортом (легкая атлетика).

Имеет жалобы на скачки артериального давлении (АД), но отмечает преимущественно низкое АД; сильные головные боли (иногда мигрени), головокружения, шаткость, “мушки в глазах", заложенность ушей, чувство нехватки воздуха, чувство “что пол плывет” (при положении стоя) и чувство “что плыву” (при положении лежа), слабость, сложность перехода из положения “сидя” в положение “лежа”. Данные симптомы отмечает на протяжении последних 5 месяцев.

До этого, за последние несколько лет, отмечает эпизодическое наличие подобных состояний (“приступов”), которые, однако, каждый раз были купированы введением этилметилгидроксипиридина сукцината внутривенно. При последнем приступе терапия имела слабый характер.

В анамнезе: заболевания желудочно-кишечного тракта.

Семейный анамнез не отягощен.

Объективно, неустойчивость в позе Ромберга, нарушения ходьбы, координации движений, когнитивные и эмоционально-волевые нарушения. Выраженный ипохондрический синдром (F45.2). Возможно наличие лабиринтной и психогенной атаксий.

По шкале Хачинского: 8 баллов (из 10).

По опроснику ММРI: выявлены ипохондрия (86/118), депрессия (75/154), истерия (86/129).

Тест Горбова-Шульте показал средние значения объема, распределения и переключения внимания.

Tест MMSE: 22 балла (из 30) - деменция легкой степени выраженности.

АД (правая рука): 100/60 мм рт.ст., АД (левая рука): 140/90 мм рт.ст. Полученные данные могут свидетельствовать о патологии периферических сосудов.

Общий анализ крови: норма, за исключением $\mathrm{Hb}=$ 156 г/л.

Биохимический анализ крови: норма.

Общий анализ мочи: норма.

ЭКГ: ритм синусовый. ЧСС $=56$ уд./мин. ЭОС горизонтальная. Отмечается нарушение процессов реполяризации, признаки гипертрофии левого желудочка.

ЭКГ (холтеровское мониторирование): за период суточного мониторирования на фоне синусового ритма с ЧСС (средняя днем 98 уд./мин, средняя ночью 68 уд./мин), нарушения ритма и проводимости не зарегистрированы. Значимых изменений QTинтервала не выявлено. АД средн. 99/66 мм рт.ст. (день) и 84/47 мм рт.ст. (ночь).

Эхо-КГ: без патологии, за исключением повышенной систолической функции левого желудочка.

РЭГ: пульсовое кровенаполнение в вертебральном бассейне справа и слева умеренно снижено. 
Тонус артерий крупного калибра незначительно повышен во всех отделах, более значительно в вертебральных. Тонус артерий мелкого и среднего калибра умеренно повышен в каротидном отделе, резко повышен в вертебральном отделе. Эластичность артерий не изменена. Венозный отток умеренно затруднен в вертебральном отделе справа. Постуральная проба положительная. Признаки внутричерепной гипертензии.

Артериография головы: МРА картина асимметрии интракраниальных сегментов позвоночных артерий $\mathrm{D}<\mathrm{S}$, с признаками локального сужения в дистальных отделах левой позвоночной артерии. Вариант развития Виллизиевого круга в виде полной задней трифуркации правой ВСА. МРА данных за наличие артерио-венозных мальформаций, аневризматического расширения, интракраниальных артерий не выявлено.

МРТ (головной мозг): МР картина нерезкой наружной гидроцефалии. МР признаки воспалительных изменений слизистой правой гайморовой пазухи и передних отделов клеток решетчатых лабиринтов. Единичная киста правой верхнечелюстной пазухи.

МРТ (шейный мозг): МР картина дистрофических изменений шейного отдела позвоночника (остеохондроз). Дорсальные протрузии С4-C5, C5-C6 и C7-Th1 дисков. МР признаки асимметрии V2 сегментов позвоночных артерий на уровне визуализации $\mathrm{D}>\mathrm{S}$.

УЗИ: БЦА проходимы. Комплекс интима-медиа задней стенки общей сонной артерии не утолщен (0,6 мм), дифференцировка на слои отчетливая. Диаметр сосудов в норме. Анатомический ход сонных артерий не нарушен. Скоростные и спектральные характеристики кровотока по сонным артериям в пределах возрастной нормы. Проксимальные отделы подключичной артерии - кровоток магистральный. Устья позвоночных артерий чистые, аномалия хода левой позвоночной артерии (Q25.8): артерия высоко входит в костный канал на уровне C4-C5 с признаками экстравазальной компрессии артерии при входе в канал не резковыраженная. Правая позвоночная артерия входит в костный канал на уровне С6-С7, ЛСК в пределах нормы. Венозные магистрали без особенностей.

Стабилометрия: ОЦД отклонен назад и вправо. Выраженная атаксия смешанного генеза с преобладанием эфферентного компонента. Значительное усиление неустойчивости при зрительной депривации. Оптокинетическая проба положительная.

ЭЭГ: легкие (негрубые) общемозговые изменения биоэлектрической активности головного мозга регуляторного характера. Реактивность конвекситальной коры на внешние раздражители сохранена. Данных за пароксизмальные формы активности, фокальное замедление корковой проводимости не выявлено. Значимой межполушарной асимметрии не выявлено.
При обсуждении возможного диагноза разными специалистами (неврологами и хирургами) выдвигались следующие: ДЭП осложненная дорсопатией шейного отдела позвоночника, расстройства вегетативной нервной системы, аномалия хода левой позвоночной артерии, хроническая ишемия головного мозга за счет нарушения кровотока в вертебробазилярной системе, вертебробазилярная недостаточность с выраженной вестибулопатией, атаксия смешенного генеза, идиопатическая интракраниальная гипертензия. Однако, окончательно был поставлен диагноз ДЭП І степени, ассоциированная с идиопатической интракраниальной гипертензией, на фоне лабильности артериального давления и ипохондрического синдрома.

В качестве немедикаментозного лечения было предложено выполнение упражнений по укреплению вестибулярного аппарата.

В качестве первой траектории лечения были назначены: ацетазоламид 500 мг утром и диосмин 600 мг утром. Выбор ацетазоламида обусловлен стандартной траекторией лечения идиопатической интракраниальной гипертензии, описанной в [4].

Через два дня АД на обеих руках сравнялось в допустимом диапазоне (разница не более 5 мм рт.ст.) и составило 125/83 мм рт.ст. Пациентка отмечает уменьшение чувства сдавливания и тяжести в голове, но головокружения остались.

Далее, были добавлены бетагистина дигидрохлорид 8 мг, N-никотиноил-гамма-аминобутировая кислота 20 мг утро + 20 мг вечер, Гинкго билоба 40 мг, настойка пустырника. Помимо этого, были назначены курсы ЛФК. АД, в среднем, составляло 106/70 мм рт.ст, за исключением нескольких эпизодов незначительного повышения.

Далее, состояние пациентки ухудшилось, появились сильные головные боли, приступы тошноты и сильное головокружение; АД $=165 / 95$ мм рт.ст. На этом этапе выясняется, что пациентка помимо назначенной терапии принимала спазмоанальгетики, объясняя это сильными головными болями, и ацетилсалициловую кислоту - “чтобы кровь разжижить, а то все проблемы, потому что кровь густая”.

Поскольку у пациентки появились признаки лабильной гипертензии, выраженные появлением пароксизмов (лабильность АД до этого отрицает, хотя не исключено, что пациентка не измеряла АД, а в те редкие разы измерения АД было нормальным), появилась возможность добавить к терапии винпоцетин 10 мг и альфадигидроэргокриптина мезилат 2 мг; дополнительно бетагистина дигидрохлорид 8 мг вечером. Также был скорректирован прием ацетазоламида - 500 мг утром, по схеме “ $2+1$ ”, то есть после двух дней приема перерыв один день.

Через 4 часа после приема отмечает улучшение, АД $=130 / 91$ мм рт.ст., еще через два часа АД = 
105/81 мм рт.ст. В последующие дни пациентка отмечает улучшение самочувствия, однако, редко отмечаются эпизодические приступы головокружения и головной боли. Рекомендован строгий контроль АД, с целью исключения приема ацетазоламида при низких значениях АД. Состояние пациентки стабильно, имеется средне прогрессирующее улучшение.

Через неделю был добавлен толперизон 150 мг. Через две недели состояние стабильно, что позволило отменить медикаментозную терапию. По данным тестов MMSE и Горбова-Шульте обнаружено улучшение когнитивных функций: 26 баллов (преддементные когнитивные нарушения) и значения объема, распределения и переключения внимания выше среднего. Через 6 месяцев состояние хорошее.

\section{Литература}

1. Classification of vascular lesions of the brain and spinal cord. In: Vascular diseases of the nervous system. М. 1975. 12-7. (In Russ.) Классификация сосудистых поражений головного и спинного мозга. В кн.: Сосудистые заболевания нервной системы. М. 1975. 12-7.

2. Neretin VYa. Complex therapy of chronic cerebral ischemia. Almanac of Clinical Medicine. 2001:4:4-6. (In Russ.) Неретин В.Я. Комплексная терапия хронической ишемии мозга. Альманах клинической медицины. 2001;4:4-6.
Таким образом, данный клинический случай представляет собой комбинацию патологий (врожденных и приобретенных) и является наглядным примером заболевания, требующего совместной работы специалистов разных областей медицины.

Конфликт интересов: автор заявляет об отсутствии потенциального конфликта интересов, требующего раскрытия в данной статье.

Благодарность. Автор выражает искреннюю благодарность участнице настоящего исследования за ее неоценимый вклад в развитие медицинской науки. Имя не раскрывается в соответствии с положениями Женевской Декларации (1948) и Хельсинской Декларации (1964) Всемирной Медицинской Ассоциации.

3. Disturbances of blood circulation in the brain and spinal cord. In: Diseases of the nervous system. Guidelines for doctors. M. 2003: 231-302. (In Russ.) Нарушения кровообращения в головном и спинном мозге. В кн.: Болезни нервной системы. Руководство для врачей. М. 2003: 231-302.

4. Binder DK, Horton JC, Lawton MT, McDermott MW. Idiopathic Intracranial Hypertension. Neurosurgery. 2004;54:538-52. 